Developing a Short-Form Situational Judgment Test to Assess Implicit Trait Policies for Agreeableness

Jan-Philipp Freudenstein \& Stefan Krumm

Freie Universität Berlin

Correspondence concerning this manuscript should be addressed to Jan-Philipp Freudenstein, jpfreudenstein@gmail.com. We are thankful to Stephan J. Motowidlo for providing us with the original test version.

\begin{abstract}
Implicit Trait Policies (ITPs) are defined as implicit beliefs about the effectiveness of behaviors that express a certain trait. They are typically assessed with Situational Judgment Tests (SJTs). However, such tests often lack sufficient psychometric properties. In this study $(N=133)$, we aimed at developing a short-form of an SJT to assess ITPs for agreeableness. Results showed, that the six-item short-version had superior model fit when compared to the original test while maintaining the same correlation to self-reported personality. Overall, the short-form is suitable for future application. Limitations and future research perspectives are discussed.
\end{abstract}




\section{Developing a Short-Form Situational Judgment Test to Assess Implicit Trait Policies for}

\section{Agreeableness}

Implicit Trait Policies (ITPs) are defined as implicit beliefs about the effectiveness of behaviors that express a certain trait (Motowidlo et al., 2006; Motowidlo \& Beier, 2010). For instance, the general belief that agreeable behavior is always more effective than disagreeable behavior, independent of the situational context, constitutes an ITP for agreeableness (Lievens, 2017; Lievens \& Motowidlo, 2016). Initially, the concept of ITPs was used to explain the relation of personality and Situational Judgment Test (SJT) scores as persons with a higher trait expression tend to have higher ITPs for that same trait (Crook et al., 2011; Kell et al., 2010; Motowidlo et al., 2006) and will thus chose trait-related behavior more often as a response in SJT items. In fact, several studies confirmed an empirical link between ITPs and personality (e.g., Martin-Raugh et al., 2016; Motowidlo et al., 2006).

ITPs are closely related to the method of SJTs (Lievens, 2017; Lievens \& Motowidlo, 2016; Motowidlo et al., 2006, 2009, 2016). Lievens and Motowidlo (2016) argued, that testtakers utilize ITPs when responding to Situational Judgment Test items. Specifically, when individuals lack knowledge for specific situations, they fall back to general beliefs about the effectiveness of behaviors (i.e., ITPs). Indeed, Motowidlo and Beier (2010) showed that a scoring key developed by students without prior job experiences predicted relevant job criteria. Within traditional SJTs, ITPs can be operationalized as the relation of a person's effectiveness rating and the degree of trait expression of a given response option (Lievens, 2017). However, some SJTs have been developed in a way that the "true" effectiveness and the trait expression of response options align perfectly (i.e., effective response options reflect high trait expression and vice versa; Motowidlo et al., 2009, 2016).

However, SJTs typically come with insufficient psychometric properties (Guenole et al., 2017). For instance, the construct validity of SJTs has recently been described as "hot mess" (McDaniel et al., 2016, p. 47). This methodological shortcoming is even more severe, 
when the assessment of a novel construct is proposed (i.e., ITPs). Thus, this study aims to develop a short and psychometrically sound measurement of ITPs for Agreeableness. We apply Ant Colony Optimization (ACO), a heuristic method, which has been demonstrated to be superior in the construction of short scales when compared to several other approaches (Olaru et al., 2015). The new short scale of ITPs for Agreeableness may be fruitful for scrutinizing underlying processes of traditional SJTs.

\section{Methods}

\section{Sample}

An a-priori power analysis $(\alpha=.05 ; 1-\beta=.80)$ with SemPower (Moshagen \& Erdfelder, 2016) revealed a required sample size of $n=109$ to detect an RMSEA $=.05$. A total of $N=133$ ( 72 female) individuals took part in the study. All data was collected online via the panel provider prolific.co. As reimbursement, participants received $£ 2$ for an average time to complete of $M=18.76(S D=9.88)$ minutes. On average, participants were $M=39.67$ $(S D=11.64$; range: $21-67)$ years old. All participants worked at least part-time in a job that required frequent contact to co-workers or customers with $M=36.21(S D=9.31)$ weekly work hours and average work experience of $M=19.68(S D=11.99)$ years. We checked for careless responding (Meade \& Craig, 2012) by asking participants whether we should use their data for analyses, checking for zero within-person variance in responses, and significant Mahalanobis distances $(p<.001)$. We excluded no participants for data analyses.

\section{Measures}

Implicit Trait Policies. We applied an SJT that has been developed to assess ITPs for Agreeableness (Motowidlo et al., 2006). This SJT consists of 22 job-related situation descriptions with four response options. Each response option reflects either agreeable or disagreeable behavior. We asked participants to rate the effectiveness of each response option in the given situation on a 7 -point scale $(1=$ very ineffective; 7 = very effective $)$. We scored 
the SJT by recoding all response options that reflect disagreeable behavior and computing mean scores for each situation descriptions. Reliability of this test was $\alpha=.89$ and $\omega=.90$.

Agreeableness. We also asked participants for self-report ratings on three pairs of adjective markers assessing agreeableness. We used those three pairs for which Wood, Nye and Saucier (2010) reported the highest average convergent correlations to three different trait assessments of agreeableness (kind-hearted, caring; giving, generous; rude, inconsiderate). Participants rated each adjective pair on a 7-point rating scale with regard to how they see themselves at work $(1=$ very uncharacteristic or untypical of me; $7=$ very characteristic or typical of me). Reliability of this scale was $\alpha=.73$ and $\omega=.73$.

\section{Data Analyses}

We used ACO to develop a valid short form of the SJT (Leite et al., 2008; Olaru et al., 2015). ACO is a heuristic method that optimizes solutions based on defined criteria instead of choosing the best out of all possible solutions. ACO is implemented in the mmas function of the R-package stuart (version 0.7.3; Schultze, 2019). We constructed a six-item version of the SJT by optimizing towards latent model fit (i.e., RMSEA and SRMR) and composite reliability of the short version. In addition, the internal consistency of response options within situation descriptions was used as heuristic information for the selection of each item. Heuristic information influences the selection probability of items independently from the quality of a certain solution (Schultze, 2017). That is, selection probability of an SJT scenario was higher with increasing internal consistency of response options within the same scenario. We determined the final solution based on 10 runs of the ACO algorithm. All confirmatory factor analyses (CFA) were estimated with lavaan (version 0.6-3; Rosseel, 2012). Due to missing values for two participants, we applied full information maximum likelihood estimation (Enders \& Bandalos, 2001). All data and R code are available on the Open Science Framework (https://osf.io/qc8x2/). 


\section{Results}

The CFA for the complete SJT with 22 items did not yield an acceptable fit; $\chi^{2}(209)=$ $392.58, p<.001 ; \mathrm{CFI}=.80 ; \mathrm{RMSEA}=.08 ; \mathrm{SRMR}=.07$. Despite the good overall reliability $(\omega=.90)$, internal consistencies for the four response options to every situation description were quite low on average $(M=.38 ; S D=.25)$. Bivariate correlations are depicted in Table 1 .

All 10 ACO runs converged to the same six-item short version (see Appendix A). This model had an excellent fit; $\chi^{2}(9)=7.31, p=.605 ; \mathrm{CFI}=1.00 ; \mathrm{RMSEA}=.00 ; \mathrm{SRMR}=.03$ The internal consistency of this short form was good but somewhat lower in comparison to the original test $(\omega=.81)$. Internal consistencies of response options within single SJT items were higher when compared to the original version $(M=.49 ; S D=.17)$. A comparison of bivariate correlations to self-report Agreeableness did not yield a significant difference between the original and short version $(z=1.02, p=.309)$.

Table 1

Descriptive Statistics and bivariate correlations

\begin{tabular}{lcccc}
\hline & $\boldsymbol{M}(\boldsymbol{S D})$ & $\mathbf{1 .}$ & $\mathbf{2 .}$ & $\mathbf{3 .}$ \\
\hline 1. ITP-SJT & $4.83(0.49)$ & - & & \\
2. ITP-SJT short & $4.93(0.67)$ & .92 & - & \\
3. Agreeableness & $5.69(1.08)$ & .26 & .23 & - \\
\hline
\end{tabular}

Notes. $n=131$. ITP $=$ Implicit Trait Policy. SJT = Situational Judgment Test.

\section{Discussion}

The aim of this study was to develop a short measure of ITPs for Agreeableness with good psychometric properties. Results showed that the newly developed short version has superior model fit in comparison to the complete SJT. Moreover, the short version retained similar properties with regard to the relation to self-report Agreeableness and was highly correlated with the original version. Thus, the short-form is suitable for future application as it 
complies with standards required for psychological assessment. Overall, results are in line with research showing that ACO can be a superior tool for the construction of valid psychological assessments (Olaru et al., 2015).

Thus far, advances in research on ITPs have been primarily made on a conceptual and theoretical level (Lievens \& Motowidlo, 2016; Motowidlo \& Beier, 2010). Although ITPs have been proposed as underlying construct of SJTs, little evidence about the relation of ITPs and SJT performance exists (cf., Motowidlo et al., 2018; Oostrom et al., 2012). Therefore, future research is needed that further dives into scrutinizing the relevance of ITPs for SJT performance. This research provides a psychometrically sound measure of ITPs for Agreeableness that may contribute to this undertaking. It was especially required when considering the fact that the assessment of ITPs relies on the same methodological approach as traditional SJTs, which typically has psychometric shortcomings (Guenole et al., 2017; McDaniel et al., 2016) and

Nevertheless, this short ITP measure should be applied with care. First, the optimized short scale was not cross-validated on a second sample. Sampling error and context effects of items that were not selected for the short scale could affect the suitability of the derived solution. Future research should pay close attention to the model fit of the short scale. Second, construct validity of the SJT was not assessed. Although we assessed self-reported Agreeableness, we did not measure ITPs for Agreeableness with different tests. Thus, the derived short scale can only be understood as psychometrically superior version of the original test. Further research is needed to assess the construct validity of this short version and ITPs in general, especially since research on ITPs lacks such studies (cf., Motowidlo et al., 2018). 


\section{References}

Crook, A. E., Beier, M. E., Cox, C. B., Kell, H. J., Hanks, A. R., \& Motowidlo, S. J. (2011). Measuring relationships between personality, knowledge, and performance using single-response situational judgment tests. International Journal of Selection and Assessment, 19(4), 363-373. https://doi.org/10.1111/j.1468-2389.2011.00565.x

Enders, C. K., \& Bandalos, D. L. (2001). The relative performance of full information maximum likelihood estimation for missing data in structural equation models. Structural Equation Modeling: A Multidisciplinary Journal, 8(3), 430-457. https://doi.org/10.1207/S15328007sem0803_5

Guenole, N., Chernyshenko, O. S., \& Weekly, J. (2017). On designing construct driven situational judgment tests: Some preliminary recommendations. International Journal of Testing, 17(3), 234-252. https://doi.org/10.1080/15305058.2017.1297817

Kell, H. J., Rittmayer, A. D., Crook, A. E., \& Motowidlo, S. J. (2010). Situational content moderates the association between the big five personality traits and behavioral effectiveness. Human Performance, 23(3), 213-228. https://doi.org/10.1080/08959285.2010.488458

Leite, W. L., Huang, I.-C., \& Marcoulides, G. A. (2008). Item selection for the development of short forms of scales using an ant colony optimization algorithm. Multivariate Behavioral Research, 43(3), 411-431. https://doi.org/10.1080/00273170802285743

Lievens, F. (2017). Assessing personality-situation interplay in personnel selection: Toward more integration into personality research. European Journal of Personality, 31(5), 424-440. https://doi.org/10.1002/per.2111

Lievens, F., \& Motowidlo, S. J. (2016). Situational judgment tests: From measures of situational judgment to measures of general domain knowledge. Industrial and Organizational Psychology: Perspectives on Science and Practice, 9(1), 3-22. https://doi.org/10.1017/iop.2015.71 
Martin-Raugh, M. P., Kell, H. J., \& Motowidlo, S. J. (2016). Prosocial knowledge mediates effects of agreeableness and emotional intelligence on prosocial behavior. Personality and Individual Differences, 90, 41-49. https://doi.org/10.1016/j.paid.2015.10.024

McDaniel, M. A., List, S. K., \& Kepes, S. (2016). The "hot mess" of situational judgment test construct validity and other issues. Industrial and Organizational Psychology, 9(1), 47-51. https://doi.org/10.1017/iop.2015.115

Meade, A. W., \& Craig, S. B. (2012). Identifying careless responses in survey data. Psychological Methods, 17(3), 437-455. https://doi.org/10.1037/a0028085

Moshagen, M., \& Erdfelder, E. (2016). A new strategy for testing structural equation models. Structural Equation Modeling: A Multidisciplinary Journal, 23(1), 54-60. https://doi.org/10.1080/10705511.2014.950896

Motowidlo, S. J., \& Beier, M. E. (2010). Differentiating specific job knowledge from implicit trait policies in procedural knowledge measured by a situational judgment test. Journal of Applied Psychology, 95(2), 321-333. https://doi.org/10.1037/a0017975

Motowidlo, S. J., Crook, A. E., Kell, H. J., \& Naemi, B. (2009). Measuring procedural knowledge more simply with a single-response situational judgment test. Journal of Business and Psychology, 24(3), 281-288. https://doi.org/10.1007/s10869-009-9106-4

Motowidlo, S. J., Ghosh, K., Mendoza, A. M., Buchanan, A. E., \& Lerma, M. N. (2016). A context-independent situational judgment test to measure prosocial implicit trait policy. Human Performance, 29(4), 331-346. https://doi.org/10.1080/08959285.2016.1165227

Motowidlo, S. J., Hooper, A. C., \& Jackson, H. L. (2006). Implicit policies about relations between personality traits and behavioral effectiveness in situational judgment items. Journal of Applied Psychology, 91(4), 749-761. https://doi.org/10.1037/00219010.91.4.749 
Motowidlo, S. J., Lievens, F., \& Ghosh, K. (2018). Prosocial implicit trait policies underlie performance on different situational judgment tests with interpersonal content. Human Performance, 31(4), 238-254. https://doi.org/10.1080/08959285.2018.1523909

Olaru, G., Witthöft, M., \& Wilhelm, O. (2015). Methods matter: Testing competing models for designing short-scale big-five assessments. Journal of Research in Personality, 59, 56-68. https://doi.org/10.1016/j.jrp.2015.09.001

Oostrom, J. K., Born, M. P., Serlie, A. W., \& van der Molen, H. T. (2012). Implicit trait policies in multimedia situational judgment tests for leadership skills: Can they predict leadership behavior? Human Performance, 25(4), 335-353.

https://doi.org/10.1080/08959285.2012.703732

Rosseel, Y. (2012). lavaan: An R package for structural equation modeling. Journal of Statistical Software, 48(2), 1-36. https://doi.org/10.18637/jss.v048.i02

Schultze, M. (2017). Constructing subtests using ant colony optimization [Doctoral dissertation, Freie Universität Berlin]. http://doi.org/10.17169/refubium-622

Schultze, M. (2019). stuart: Subtests using algorithmic rummaging techniques. https://cran.rproject.org/package=stuart

Wood, D., Nye, C. D., \& Saucier, G. (2010). Identification and measurement of a more comprehensive set of person-descriptive trait markers from the english lexicon. Journal of Research in Personality, 44(2), 258-272.

https://doi.org/10.1016/j.jrp.2010.02.003 


\section{Appendix A}

\section{Situational Judgment Test Items}

\section{Instruction}

This questionnaire asks for your opinions about how to deal with people at work. It contains descriptions of some awkward or difficult interpersonal situations that might happen in large work organizations and alternative actions that a person could take to deal with them. It asks you how effective the actions are for dealing with each situation.

Each interpersonal situation described in this questionnaire has four action alternatives listed directly below it. Please write a number from 1 to 7 on the lines next to the action alternatives to show how effective you think they are, where...

\begin{tabular}{lcl}
$7=$ very effective & $4=$ neither effective & $3=$ slightly ineffective \\
$6=$ somewhat effective & nor ineffective & $2=$ somewhat ineffective \\
$5=$ slightly effective & & $1=$ very ineffective \\
\hline
\end{tabular}

Item Situation Description Response Options

\begin{tabular}{|c|c|c|}
\hline 1 & $\begin{array}{l}\text { Your recently appointed superior } \\
\text { has had many disagreements with } \\
\text { you and your colleagues, and } \\
\text { usually supports her position by } \\
\text { indicating that her view is "how } \\
\text { things were done" in her previous } \\
\text { job environment. In a meeting with } \\
\text { you and your team, after you } \\
\text { propose a way to solve a procedural } \\
\text { problem, she said, "no, we'll do it } \\
\text { the way I've always done it". You } \\
\text { should... }\end{array}$ & $\begin{array}{l}\text { (a) tell her that in this case her } \\
\text { suggestions are simply wrong. }(-) \\
\text { (b) meet with her privately and explain } \\
\text { that you feel she is not accepting any } \\
\text { input from the team and this is } \\
\text { hurting morale. }(+) \\
\text { (c) tell her that you will be looking for a } \\
\text { new assignment if this is the way } \\
\text { you will be working together. }(-) \\
\text { (d) meet with her privately and explain } \\
\text { the effect she is having on you and } \\
\text { the entire team. (+) }\end{array}$ \\
\hline 4 & $\begin{array}{l}\text { You and your colleague, who is at } \\
\text { the same level in the organization, } \\
\text { "share" the same clerk. One day the } \\
\text { clerk takes you aside and tells you } \\
\text { that your colleague told her that his } \\
\text { requests should take priority over } \\
\text { yours. You should... }\end{array}$ & $\begin{array}{l}\text { (a) meet with your colleague to discuss } \\
\text { the situation and suggest setting up a } \\
\text { schedule for the clerk so you can } \\
\text { coordinate your tasks more } \\
\text { efficiently. (+) } \\
\text { (b) ask your colleague if he is working } \\
\text { on a special project, deadline, or is } \\
\text { planning to be away so that you can } \\
\text { find a compromise that would suit } \\
\text { you both. (+) } \\
\text { (c) tell the clerk to ignore the comment } \\
\text { made by your colleague and to treat } \\
\text { both of your requests equally. }(-) \\
\text { (d) get a written statement from your } \\
\text { manager of what the clerk's } \\
\text { priorities are and show it to your } \\
\text { colleague. }(-)\end{array}$ \\
\hline
\end{tabular}


Appendix A (continued)

You suspect that your manager has
been taking credit for documents
that you have prepared and ideas
that you have generated. One
afternoon you notice him attaching
his business card to a presentation
that you prepared. You should...
(a) speak with your manager and tell him that the lack of recognition makes you feel unmotivated at work. $(+)$
(b) tell your manger that you think his behavior is unethical and that you will be filing a complaint. (-)
(c) tell your manager how much work you put into the presentation and that you would appreciate the recognition for it. (+)

(d) tell your manager that if he doesn't stop attaching his business cards to your presentations, you will have no alternative but to report his actions. $(-)$

\begin{tabular}{|c|c|c|}
\hline 13 & $\begin{array}{l}\text { You are the newest member of a } \\
\text { project team and you are at your } \\
\text { first team meeting. You have just } \\
\text { started presenting what you think is } \\
\text { a good idea when you are } \\
\text { interrupted by another member who } \\
\text { tells you that, because you are so } \\
\text { new and inexperienced, you should } \\
\text { sit back quietly and learn. You } \\
\text { should... }\end{array}$ & $\begin{array}{l}\text { (a) tell the individual that the group, not } \\
\text { one person, should judge the merit of } \\
\text { your idea. (-) } \\
\text { (b) speak privately with the individual } \\
\text { after the meeting about how their } \\
\text { comments made you feel. (+) } \\
\text { (c) acknowledge that you are new and } \\
\text { ask the entire group to listen to you } \\
\text { as an equal member of the team. (+) } \\
\text { (d) tell the individual privately that you } \\
\text { expect an apology in front of the } \\
\text { other team members at the next } \\
\text { meeting. }(-)\end{array}$ \\
\hline 20 & $\begin{array}{l}\text { You are in charge of a meeting with } \\
\text { six people from other departments. } \\
\text { One of them has a very blunt way } \\
\text { of announcing that something that } \\
\text { was said is stupid or that } \\
\text { somebody's idea just won't work. } \\
\text { By the time the meeting is half } \\
\text { over, he has done this twice in } \\
\text { connection with remarks made by } \\
\text { two different participants. The } \\
\text { meeting is scheduled to continue } \\
\text { for another thirty minutes. You } \\
\text { should... }\end{array}$ & $\begin{array}{l}\text { (a) during a break or after the meeting, } \\
\text { explain to him that you appreciate } \\
\text { his point of view, but that his } \\
\text { comments are hurting the other } \\
\text { coworkers. (+) } \\
\text { (b) during the meeting, tell him to keep } \\
\text { his rude comments to himself or he } \\
\text { won't have a job anymore. (-) } \\
\text { (c) during a break or after the meeting, } \\
\text { tell him that his comments were } \\
\text { hurting group participation, and ask } \\
\text { him to phrase his criticisms } \\
\text { differently. (+) } \\
\text { (d) during the meeting, ask him to leave } \\
\text { the meeting. (-) }\end{array}$ \\
\hline
\end{tabular}


Appendix A (continued)

\begin{tabular}{|c|c|c|}
\hline 21 & $\begin{array}{l}\text { You have recently been promoted } \\
\text { to a management job. On the } \\
\text { second day in your new position, } \\
\text { one of your new subordinate team } \\
\text { members comes into your office } \\
\text { and tells you she thinks she should } \\
\text { have been promoted to your } \\
\text { position instead of you because she } \\
\text { has more seniority and technical } \\
\text { experience. You should... }\end{array}$ & $\begin{array}{l}\text { (a) listen to her concerns, letting her } \\
\text { know that her experience is valued } \\
\text { and where possible you would like to } \\
\text { help with her career development. } \\
\text { (+) } \\
\text { (b) acknowledge her technical } \\
\text { experience and affirm her value to } \\
\text { the team. (+) } \\
\text { (c) explain to her that you are not } \\
\text { responsible for the selection process } \\
\text { and that she should be taking her } \\
\text { concerns to the appropriate people } \\
\text { elsewhere. (-) } \\
\text { (d) tell her that you went through the } \\
\text { proper channels to get the promotion } \\
\text { and that despite her frustration she } \\
\text { should treat you as her supervisor. (-) }\end{array}$ \\
\hline
\end{tabular}

Notes. Scoring instructions in parentheses. + Response rating is included in the sum score. Reverse-coded response rating is included in the sum score. These items can be applied for research purposes by citing this manuscript and Motowidlo et al. (2006). Stephan J. Motowidlo holds the copyright on all items. 